acromion process down the front of the arm, joined at right angles below by a deep external and a superficial internal incision, meeting at the posterior fold of the axilla. The outer flap thus formed was then dissected up, the head of the humerus disarticulated, and the inner flap was finally completely severed. Drainage-tubes were inserted. The whole operation was done under carbolic-acid spray, the patient being under chloroform. The temperature was $99 \cdot 4^{\circ} \mathrm{F}$. at night.

On the $22 \mathrm{nd}$ and $23 \mathrm{rd}$ the temperature did not rise above $100^{\circ} \mathrm{F}$. On the latter day the wound was dressed antiseptically, and looked remarkably well. There was very slight discharge. The next day the temperature was down to $99^{\circ} \mathrm{F}$.; pulse 108 , of fair force, regular ; tongue clean and moist; no nausea, headache, or rigors. On the 29 th the discharge began to be somewhat offensive, and it was found necessary to dress the wound daily. The first suture was then removed. The flaps were quite healthy. The general condition also was excellent, the temperature never rising above $100^{\circ}$. The remaining stitches were removed on Jan. 2nd.

From the 3lst of December the wound had been dressed every second day, the discharge from the lower or posterior extremity of the wound, which at times was very offensive, necessitating this.

On Jan. 4th the temperature rose to $101^{\circ} \mathrm{F}$., followed by a further rise the next night to $102^{\circ} \mathrm{F}$. A bag of pus had collected at the dependent extremity of the wound. On the 7th the antiseptic spray was discontinued, and the wound simply syringed out, and dressed with carbolic lotion. A firm pad was strapped over the sac at the posterior extremity of the wound.

The wound was now dressed twice a day. From this date the discharge became less in quantity and less offensive, the flaps were healthy, the cavity at the extremity granulating up well. The constitutional condition was good. On the 17 th patient got up for the first time. She continued to improve, and on Feb. 6th was discharged. 'The wound was nearly healed, and the cavity was almost filled up. The woman had instructions to dress the wound herself occasionally with a lotion of chlorate of soda, and to report herself from time to time at the hospital.

Pemarls.-Mr. Norton said he had no difficulty in this case in determining the time at which amputation should be performeu. As a rule it was advisable in traumatic gangrene to amputate as soon as gangrene set in, but here the erysipelas, which had extended far up the upper arm when the case came first under his observation, would doubtless have brought about a fatal termination had the operation been performed at that time. He preferred to wait and by proper treatment and disinfecting to endeavour to limit the spread of the disease. His expectations were realised, and the erysipelas subsided, leaving the gangrane, however, still in progress. It was true no line of demarcation had formed at the tima of the operation, but then it was sufficiently evident that amputation would have to be performed; and whilst on the one hand the health of the patient was excellent, considering the state of the disease, the mass of gangrene could not but prove deleterious, and he feared that blood-poisoning might take place if the operation were further delayed. He considered the tissues around the shoulder-joint in a healthy condition. He was always anxious when possible to save even two or three inches of the humerus for the purpose of applying an artificial limb, and, possibly, it might have been done even in this case, but there was always more danger of absorption when a bone was cut through than when amputation was performed at a joint. The tissues were still diseased some five inches below the shoulder-joint, and to operate in that recion would have both endangered the flaps, and, considering the state of the limb, more than probably given rise to osteomyelitis; therefore he felt compelled to remove the limb at the shoulder-joint.

\section{YORK COUNTY HOSPITAL.}

POPLITEAL ANEURISM CURED BY APPLICATION OF ESMARCH'S ELASTIC BANDAGE AND DIGITAL COMPRESSION.

(Under the care of Mr. HEwETsoN.)

IT will be noticed in the following case, for the notes of which we are indebted to Mr. F. H. Weekes, house-surgeon, that the application of the elastic bandage for eighty minutes effected a great change in the character of the aneurism, although consolidation was scarcely sufficient to justify a discontinuance of treatment. A few hours of digital compression completed the cure. Such a result by such simpie means (rendered painless through chloroform) is highly satisfactory and gratifying, whether it be considered from the standpoint of modern practice or from that of a hundred years ago, when the cure of aneurism was almost hopeless.

R. M-, a healthy-looking man, aged twenty-six, formerly in the navy, was admitted on May 22nd, with an aneurism of the left popliteal artery, first noticed two months before. There was no history of injury, but a wellmarked one of syphilis existed. The left knee measured in circumference an inch and a quarter larger round than the right, and there was, moreover, slight odema, with consider able pain in the affected leg. The heart and the other arteries were, as far as could be ascertained, healthy

May 26th.-At 9.20 A.M. the affected limb was lightly covered with a flannel roller, and Esmarch's elastic bandage was applied firmly from the toes to about the head of the fibula. The patient then stood up, and the bandage was put on from about three inches above the patella up to the groin, at which spot the elastic ligature was applied, so as completely to stop all pulsation in the aneurism below. By these means an interval of seven inches opposite the anenrism at the knee was left unbandaged.-A.t 9.30 there was great pain in leg, and half a grain of morphia was given subcu. taneously; ten minutes later the pain became intolerable, so that the patient was placed under the influence of chloroform, and kept so until the bandages were removed at 10.30 (eighty minutes after application), when the femoral artery was compressed in the groin. The sac now seemed to be more solid than before, but when the femoral artery was allowed to beat once, a distinct, although feeble, wave could be felt in the aneurism. Digital compression in the groin was, therefore, begun, and kept up energetically by Messrs. Rowe, Shawn, Spencer, and others - At 4.80 P.M., after six hours of digital pressure, the aneurism was examined, and when the femoral artery was allowed to beat, the sac was found to be quite firm, and free from all pulsation. For the sake of safety, however, compression in the groin was continued until 10 P.M., when it was finally stopped.

The limb was wrapped in cotton-wool, elevated, and a quarter of a grain of morphia was biven. He had a good night's rest, and next day the limb was warm and the sat: hard ; behind the latter a small anastomosing artery conld be felt, and another a little to the inner side of the patella. The heart-sounds were normal.

On June 8th the sac was both harder and smaller. The patient got up from bed nine days later. He was, able to walk with ease, complaining only of slight jumbuess in the leg. Neither the posterior nor the anterior tilial artery could be felt to beat. He left the huspital on the $18 \mathrm{th}$.

\section{GRTMSBY AND DISTMIET HOSPTTAL.}

COMPOUND FRACTURE OF SXLLL; CONOUSSION OF BRAIN REOOVERY.

(Under the care of Mr. R. BROCKLESPY.)

For the following notes we are indebted to Theophilus Bacon, M.D., C.M., house-surgeon.

W. S- aged twenty-one, fisherman, was admitted at 1.30 A.M. on Feb. 27 th, 1879 , suffering from a severe compound fracture of the vault of the skull and concussion of brain, the injury having been received on the $25 \mathrm{th}$ at sea by a blow from a winch-handle.

On admission he was insensible, the pulse small, breathing quiet, body fairly warm; the pupils responded slowly to light, and the limbs retracted on stimulus. On examination there were found two parallel wounds of the scalp, each about an inch and a half long, running obliquely downwards and forwards from the vertex to the frontal bone. These wounds were filled with clotted blond, and both eyes were considerably ecchymosed. A finger passed into the wounds found an undepressed fracture extending from the vertex running downwards and forwards to the frontal bone, where it bifurcated, the two limbs of the inverted $V$ going to each superciliary ridge.

During the examination the patient moved his arms across his chest. On being interrogated rather loudly, be answered in a very incoherent manner. Directly afterwards he spat up a quantity of dark semifluid bluod.

On being put to bed in the darkened ward, lot-water 
bottles were applied to his feet and the ice-cap to his head. Mr. Brocklesby saw him a few hours afterwards, and prescribed a full dose of white mixture at once, and a mixture containing solution of acetate of ammonia and spirits of nitrous ether and of chloroform every four hours. As the matient was very plethoric, wet cupping to the nape of the neck was applied, and an ounce and a half of blood was lrawn. When the man attempted to swallow the liquid was srourted out again, and at intervals for a period of two or three days he spat up a quantity of dark half-clotted blood.

The temperature on the evening of admission was $99 \cdot 6^{\circ}$.

Next morning it was $103 \cdot 2^{\circ}$; evening, $99^{\circ}$.

On March list the temperature in the morning was $98.2^{\circ}$, and in the evening $97.4^{\circ}$; the patient was a little more conscious, spat up blood, and his bowels were slightly moved.

March 2nd.-Temperature in the morning, $97 \cdot 6^{\circ}$; evening, $98 \cdot 6^{\circ}$. He swallowed with difficulty, and was restless. Later in the day he sang.

3rd.-Morning temperature $98 \cdot 2^{\circ}$; evening, $99 \cdot 3^{\circ}$. Bowels moved unconsciously. Was very violent, and had to be continually watched.

Next day he was so violent that his arms had to be fastened to the bed, as he endeavoured to reopen the wounds. Would not allow his temperature to be taken. The swelling had subsided in the left eye, but had increased in the right. Bowels moved unconsciously; urine normal.

On the 5th the wounds in the head were suppurating; a charcoal poultice was applied. Patient still very violent, swearing at everybody, and using abominable language.

9th.-Temperature : morning, $99.2^{\circ}$; evening, $101^{\circ}$. The swelling in the left eye had completely disappeared; that of the right eye was increased, so that he could not open the lids. As there was a feeling of fluctuation, an incision along the line of the eyelashes was made, and a large quantity of pus flowed out. The upper wound of the scalp was gaping; at the bottom the dura mater was seen, the edges of the fracture being about one-sixth of an inch wide.

Next day pus discharged abundantly from the incision made in the eyelid. The eye washed out with tepid milkand-water. The lower wound of scalp was nearly healed up. Bowels well opened. Patient was quite conscious ; appetite good ; complained of hunger, but only allowed light diet.

11th.-Temperature : morning, $998^{\circ}$; evening, $100 \cdot 2^{\circ}$. On raising the right eyelid a large ulcer on the cornea was seen, which was touched with a solution of nitrate of silver. A sore having formed on the occiput, it was dressed with simple ointment, and a water-pillow was ordered for the head.

From this date the man steadily improved, and became quite rational. The swelling in the eyelid gradually subsided, but on opening the lids, in addition to the corneal ulcer, there was found a well-marked symblepharon at the inner canthus.

On the 29th the patient was moved into the Yarborough ward. Was able to sit up in bed. Both wounds in the scalp were healed up. A little pus still discharged from the eyelid. In a few days he was able to go into the garden, and was discharged cured on April 14th.

\section{attledical Soxictirs.}

\section{OBSTETRICAL SOCIETY OF LONDON.}

\section{THE USE OF THE FORCEPS.} (Concluded from page 51.)

Dr. Clefveland.-Sir, before the commencement of this debate, I should have thought, in common with other Fellows of the Society who have taken part in or listened to the discussions that have not unfrequently taken place here on the principles that should guide us in the use of the forceps, that it would have been scarcely necessary for us to have devoted three evenings to this subject; but I confess, after having heard so many differences of opinion, I have come to the conclusion that that idea was not well founded. I further think that Dr. Barnes has shown great judgment in drawing up with the care he has exhibited these general propositions; and I think that the last proposition, the one that has been read by Dr. Hicks, with the corollary attached to it, has not been sufficiently noticed by the speakers that have preceded me. He says that "in proportion as the head is arrested high in the pelvis, in the brim or above the brim, the necessity, the utility, and the safety of the forceps become less frequent"; and then there is the corollary, that " increasing caution in determining on the use of the forceps, and greater skill in carrying out the operation, are called for." If this means anything, it means that the operation is not to be lightly undertaken, that it is one that ought to be well considered, and only to be done by persons who are thoroughly skilled in the use of the instrument. I think the case is somewhat like that of a patient who has stone in the bladder. In such a case, the best thing is to lave the stone removed, either by lithotomy or lithotrity; but it would not be the best thing possible if the operation were not done by a skilful person; the patient might live a con. siderable time with the stone in the bladder, and be better off than if he had the operation performed. Now I would say that if some of us who had settled convictions at the commencement of the debate upon certain practical points, such, for instance, as the use of the forceps and compression, have had those convictions somewhat disturbed by what we have heard from different authorities, men of great reputation, still, I believe that on the whole we shall be pretty well agreed that in a case where the head is well in the pelvis, where there is what is understood by a lingering labour, where the patient is carefully watched and appears to be kept up by suitable nourishment, if in such a case you come to a thorough stoppage, no progress being made, and you are satisfied that the uterus has done its best, I think there can be no doubt that the use of the forceps is better than any of its alternatives. But between such a case as that and the contested point where the os is not well dilated, and where arrest is above the brim, there appears to me to be a large class of cases in which great service is done by the use of the forceps. And here let me say that we have not discriminated sufficiently between the long and the short forceps. There are cases in which the long forceps will reach the child and where the short forceps will not be of any avail. Sometimes, indeed, I have to ask myself the question whether we should not be better off if there were no short forceps at all. I have myself seen people waiting and waiting until the head comes within reach of the short forceps, and a great deal of time has been lost, and a great deal of danger incurred by the patient. For many years I have not used the short forceps, and I have never found a case in which the long forceps would not answer both purposes. With regard to the contested point, I may say that I think it is very rare indeed that an operation is required for purely lingering labour, but I do not believe for a moment that in skilful hands any mischief is likely to accrue to the patient by the use of the instrument if it is necessary to employ it.

Dr. DALY.-I will only occupy two or three minutes in replying to some of the figures of Dr. Roper. I have not had 10,000 cases, but in 1700 cases that have come under my private care I have used the forceps with what some people would call extreme frequency. During a practice of fifteen years I have used the forceps in 10 per cent. of my cases, and the result of my practice has been that I have only lost two forceps cases. One was a case in which I put on the forceps for hæmorrhage, and in the other case I am sure the forceps had nothing at all to do with the death. I think it is well for the Society to know that men may use the forceps with even much greater frequency than I have done. I have been looking over the statistics of some medical men connected with this Society. A gentleman recently showed me his list of 260 deliveries. He had used the forceps in exactly 40 cases without a single maternal death and without a single still-birth. Now if the forceps were on its trial to-night, as Dr. Roper would suppose, I do not think we should have such statistics as those. From what one has heard from the different speakers who have addressed the meeting, one really would think that Dr. Barnes's book had never been written, and that we had not your book, Sir, on midwifery before us. The great value of the forceps is that they save the woman an enormous amount of suffering. I have not heard that point stated by any speaker, although I am aware you have mentioned it in a paper read to this Society. The woman goes on for hours 